\title{
Cyclical fatigue of annealed and of thermally tempered soda- lime-silica glass
}

\author{
Jens Schneider ${ }^{1}$ and Jonas Hilcken ${ }^{1}$ \\ ${ }^{1}$ ISM+D Institute of Structural Mechanics and Design, Glass Competence Center, TU Darmstadt, Germany
}

\begin{abstract}
We present experimental and theoretical investigations on the cyclic fatigue of annealed and of thermally tempered soda-lime-silica glass. Static fatigue due to subcritical crack growth at micro cracks significantly decreases the macroscopic strength of soda-lime-silica glass and causes a time-dependent strength reduction. A subsequent thermal tempering process is typically used to induce residual surface compression stresses, which inhibit the crack growth of surface cracks, and corresponding bulk tension stresses. From the experimental results we show that the existing models for static fatigue used in linear elastic fracture mechanics can be used for the lifetime prediction of cyclically loaded annealed glass and thermally tempered glass, although the (static) crack growth exponent slightly decreases in cyclic loading. The equivalent duration of tensile stress at the crack tip of a micro crack governs the crack growths and not the number of cycles. The threshold for subcritical crack growth determined from the cyclic experiments was found to be in good agreement with data from literature. But unlike in strength tests with singular and quasi-static re-loading, it could be found that periodic loading with load free intervals does not lead to a strength increase by crack healing effects. Based on the results, an engineering design concept for cyclically loaded glass is presented.
\end{abstract}

\section{Introduction}

\subsection{Motivation}

Flat glass, whose dimensions can reach up to $3.25 \mathrm{~m} \mathrm{x}$ $20 \mathrm{~m}$ today, is increasingly taking over load-bearing functions in structures. For their design and dimensioning, verification methods are currently being developed to develop an Eurocode Structural Glass taking into account the brittle characteristics of glass [1]. Although periodic loading, e.g. from wind or live loads, can be decisive for glass design, very few scientific investigations are currently available on the cyclic fatigue of glass [2-5]. One reason is the complex experimental determination of the relevant parameters in cyclic fatigue tests. We recently determined the parameters for the most important glass in the building sector and the automotive industry (soda-lime-silicate glass) in extensive test series and, based on linear-elastic fracture mechanics, converted the findings into a design concept [6]. This article summarizes the most important findings of the experimental and theoretical investigations and the design concept, which can be integrated in the existing DIN 18008 [7] and the future Eurocode (now CEN-TS [1]).

\subsection{Strength of Glass}

The strength of glass preliminary depends on the presence of micro-cracks (in practice typically $4 \mu \mathrm{m}$ to $100 \mu \mathrm{m})$ on the glass surface, the formation of which is unavoidable during production, transport, assembly and use. In the case of tensile stresses on the glass surface, the linear fracture mechanics and its $K$-concept provide a suitable model for determining the critical crack depths and geometries, which lead to (macroscopically) sudden failure due to supercritical, dynamic crack growth. The following failure condition must be fulfilled in mode I, which is the mode applicable for most glass cracks and loading in practice:

$$
K_{\mathrm{I}}=\sigma \cdot Y \cdot \sqrt{\pi a}<K_{\mathrm{Ic}}
$$

where

$K_{I} \quad$ stress intensity factor

$\sigma \quad$ tensile stress perpendicular to crack direction

$Y$ geometry factor

a crack depth

$K_{\text {Ic }}$ critical stress intensity factor, $K_{\mathrm{Ic}}=0,75 \mathrm{MPa} \mathrm{m}^{1 / 2}$ for soda-lime-silica glass

However, this model of linear elastic fracture mechanics is only valid for conditions in which no water molecules can reach the crack tip. If this is not the case, as is the

Corresponding author: schneider@ismd.tu-darmstadt.de 
case for almost all applications in the building and automotive industry, crack growth can also occur below $K_{I c}$. This depends on the stress intensity and the duration of the tensile stress at the crack tip of a micro-crack, since it depends on diffusion processes of the damaging medium (here: water) to the crack tip. However, it does not yet lead to instantaneous failure and is therefore called subcritical crack growth. The limit of stress intensity below which no subcritical crack growth takes place is called $K_{I 0}$ (fatigue threshold). For soda-lime silicate glass it ranges from $K_{I 0}=0.2$ to $0.4 \mathrm{MPa} \mathrm{m}^{1 / 2}[8$ $11]$.

\section{Experimental investigations}

\subsection{Defined pre-damage of the samples}

The randomly distributed micro-cracks on the glass surface and their randomly distributed geometry and depth cause a very strong scattering and a size effect of the glass strength, thus larger areas under tensile stress having a larger probability of failure than smaller areas. This is very unfavourable for cyclic fatigue tests, as very short lifetimes (seconds) or very long lifetimes (years) can occur with real geometrical and material parameters. Therefore, a method for a defined pre-damage was developed in which the glass sample is indented and scratched with a conical diamond $\left(120^{\circ}\right.$, tip radius of $r_{S}=$ $5 \mu \mathrm{m})$ at a defined vertical indentation force of $500 \mathrm{mN}$ in an Universal Surface Tester (UST), see $[12,13])$. The sample is scratched for a length of $2 \mathrm{~mm}$ (Fig. 1). The resulting initial vertical median cracks below the scratches thus are well reproducible and result in crack depths of $a=40-50 \mu \mathrm{m}$. This leads to a macroscopic tensile strength of about $45 \mathrm{MPa}$ of annealed float glass (ANG) and of about $120 \mathrm{MPa}$ for thermally fully tempered glass (FTG) in a coaxial double ring bending test applying a stress rate of $2 \mathrm{MPa} / \mathrm{s}$. This corresponds to the $5 \%$-fractile of the bending strength of ANG and FTG defined in product and design standards for glasses from soda-lime silicate glass [7, 14]. The coefficient of variation of the tensile strength applying this pre-damage method is less than $4 \%$.

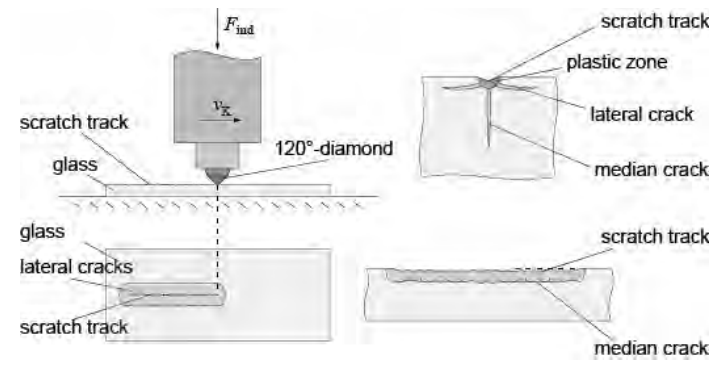

Fig. 1. Defined pre-damage by indentation and scratching using an Universal Surface Tester (UST)

\subsection{Cyclic fatigue tests}

The experimental investigations were carried out in a coaxial double ring bending test for annealed glass
(ANG) and thermally tempered glass (FTG). FTG was also tested in a three-point bending test. By testing in the double ring bending test (Fig. 2), an influence of the orientation of the cracks and an edge influence from predamage of the glass edges can be excluded, because for small deformation of the sample, an equibiaxial tensile stress field is created within the load ring on the lower side of the specimen. With our test setup, however, only tension stresses (stress ratio $R>0$ ) and frequencies up to $1 \mathrm{~Hz}$ could be applied. Therefore, the additional threepoint bending tests with frequencies up to $15 \mathrm{~Hz}$ and with alternating loads $(R<0)$ were carried out for FTG. The glasses tested were commercially available, annealed and thermally tempered soda-lime-silicate glasses with a nominal thickness of $d=6 \mathrm{~mm}$, which were produced in a float process. The so-called gas side was set under tension in order to exclude influences from surface damages from on the tin bath side of the float process, where the transportation rollers in the cooling section can induce significant micro-cracks.

Preliminary investigations had shown that - based on the chosen method of pre-damaging- neither the glass thickness nor the respective surface (roller side, the side facing to the rollers for thermally tempered glass) had any influence. The residual stresses were identified from stress optical measurements using a scattered light polariscope (SCALP-04, [17]).

The investigations were carried out at standard ambient conditions in a specially manufactured test chamber under defined humidity in order to specifically influence the subcritical crack growth. In addition, for each specimen subjected to cyclic fatigue, a reference specimen was tested until failure under quasi-static ramp loading at a stress rate of $2 \mathrm{MPa} / \mathrm{s}$. Table 1 shows relevant investigation parameters and the most important observed effects.

Table 1: Experimental parameters and observations

\begin{tabular}{|l|c|l|}
\hline \multicolumn{1}{|c|}{ Type } & Parameter & \multicolumn{1}{c|}{ Observation } \\
\hline $\begin{array}{l}\text { Residual } \\
\text { stresses }\end{array}$ & $\begin{array}{c}\text { Residual surface } \\
\text { compression stress } \\
\text { FTG: up to }-110 \mathrm{MPa} a\end{array}$ & $\begin{array}{l}\text { Increasing surface } \\
\text { compression } \\
\text { stresses increase } \\
\text { the fatigue } \\
\text { lifetime }\end{array}$ \\
\hline Stress ratio $R$ & $-1 / 0 / 0,5 / 0,73 / 0,8$ & $\begin{array}{l}\text { Increasing } R \\
\text { reduces the fatigue } \\
\text { lifetime }\end{array}$ \\
\hline $\begin{array}{l}\text { Form of load } \\
\text { function }\end{array}$ & $\begin{array}{c}\text { Sinus, Triangular, } \\
\text { Trapezoidal function }\end{array}$ & $\begin{array}{l}\text { Increasing fullness } \\
\text { of the load } \\
\text { function reduces } \\
\text { the fatigue } \\
\text { lifetime }\end{array}$ \\
\hline Frequency & $0,01 \mathrm{~Hz}$ to $15 \mathrm{~Hz}$ & $\begin{array}{l}\text { No significant } \\
\text { influence }\end{array}$ \\
\hline $\begin{array}{l}\text { Environmental } \\
\text { conditions }\end{array}$ & $\begin{array}{l}\text { } \% \text { - } 100 \% \\
\text { rel. humidity }\end{array}$ & $\begin{array}{l}\text { Increasing } \\
\text { humidity reduces } \\
\text { the fatigue } \\
\text { lifetime }\end{array}$ \\
\hline $\begin{array}{l}\text { Load free } \\
\text { intervals } \\
\text { between load } \\
\text { cycles }\end{array}$ & 1 hour, 1 day, 1 week & $\begin{array}{l}\text { No crack healing } \\
\text { effects compared } \\
\text { to continuous load } \\
\text { cycles }\end{array}$ \\
\hline
\end{tabular}



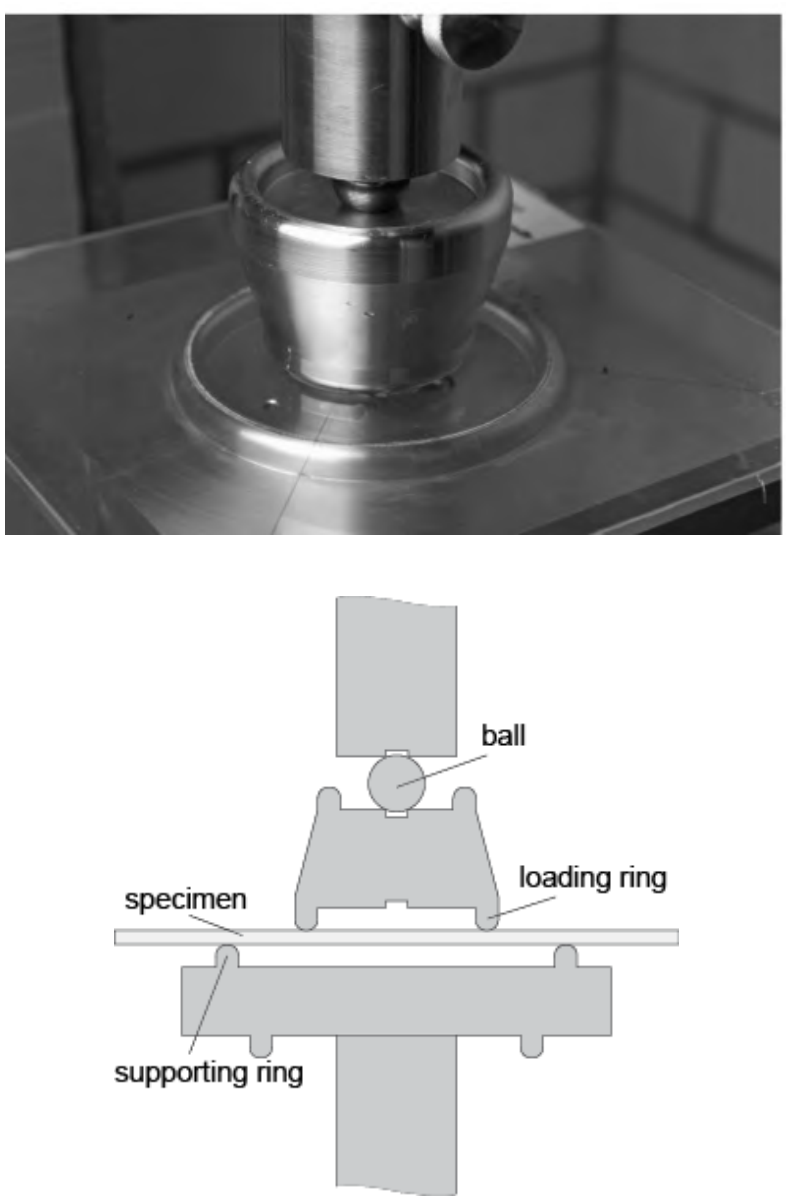

Fig. 2: Coaxial double ring bending test, $r_{\text {loading ring }}=80 \mathrm{~mm}$, $r_{\text {supporting ring }} 160=m m$ laboratory setup, section (below)

The investigations have clearly shown that it is not the number of load cycles that is decisive for failure, but the equivalent duration of tensile stress at the crack tip of a micro-crack. Therefore, the term cyclic service lifetime $t_{f c}$ is used in the following. The results with regard to the form of the ambient conditions (Fig. 3) and of the load function (Fig. 4) as well as the influence of residual stresses (Fig. 5, 6) meet expectations, as they correspond to those of dynamic fatigue tests at a constant stress rate. In the diagrams, the cyclic failure stress $\sigma_{\max }$ is normalized to the quasi-static tensile strength $\sigma_{f q s}$.

In contrast to simple reloading under quasi-static loading, however, no strength increase due to crack healing effects could observed applying stress-free intervals by loading interruption during cyclic loading (Fig. 7, 8), which are frequently described in literature $[14,15,18,19]$.

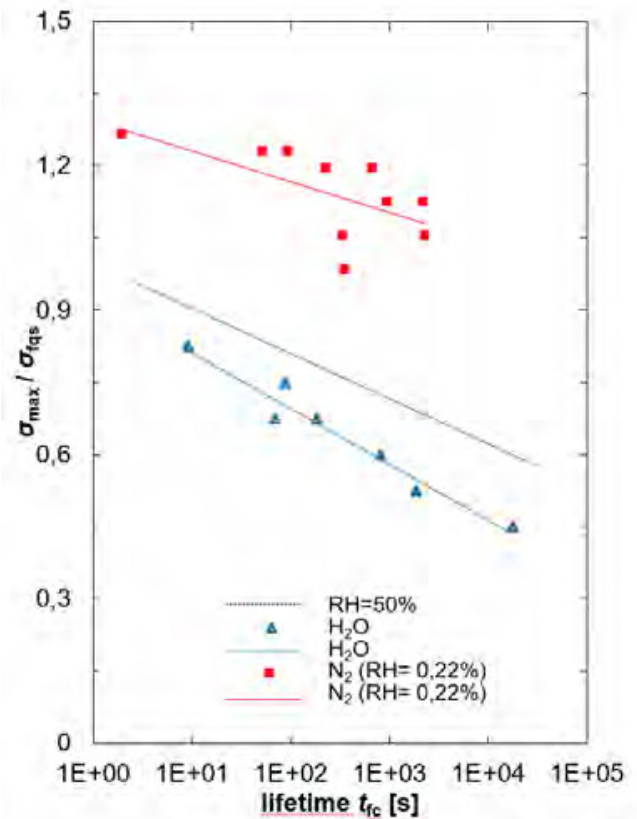

Fig. 3: Influence of the type of the ambient conditions on the lifetime of cyclically loaded annealed glass; $R H$ rel. hum.; $\mathrm{N}_{2}$ tested in nitrogen atmosphere; $\mathrm{H}_{2} \mathrm{O}$ tested with liquid demineralized water on the sample

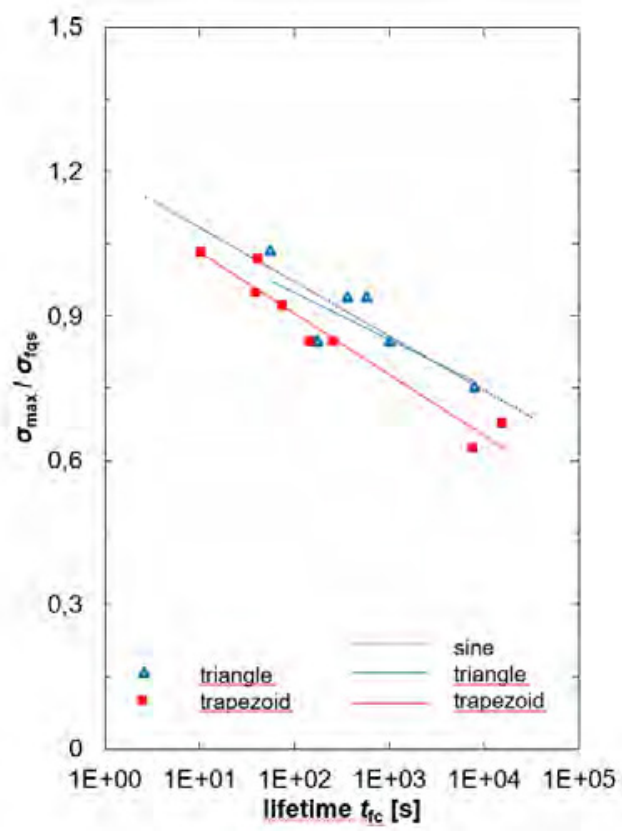

Fig. 4: Influence of the load function on the lifetime of cyclically loaded annealed glass 


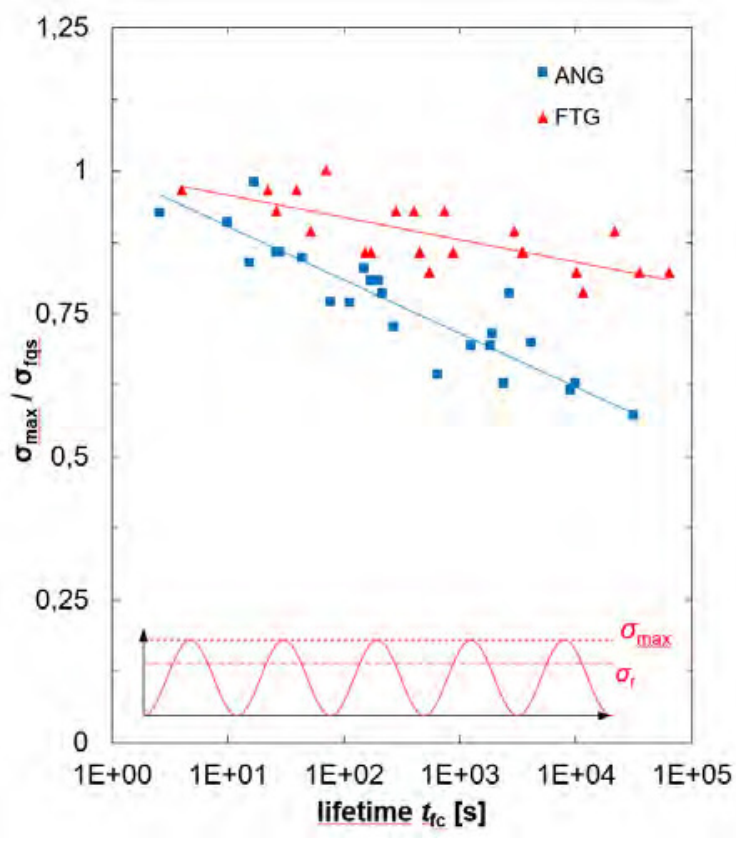

Fig. 5: Influence of thermally induced residual surface compressive stresses (ANG: squares, FTG: triangles)

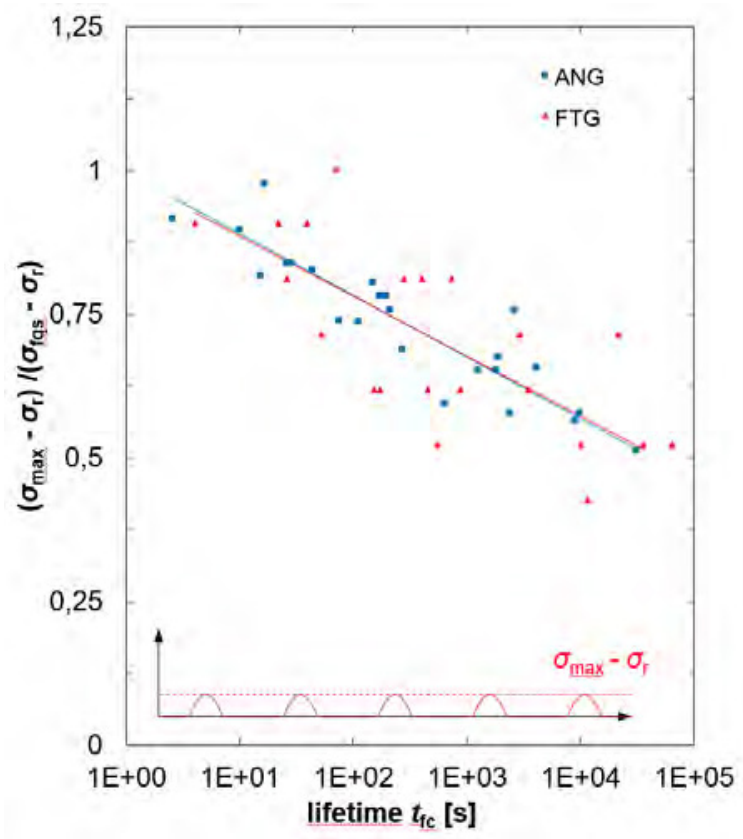

Fig. 6: Representation of Fig. 5 for "effective stresses" after deduction of the thermally induced residual surface compressive stresses $\sigma_{\text {res }}$ measured with a scattered light polariscope [17]

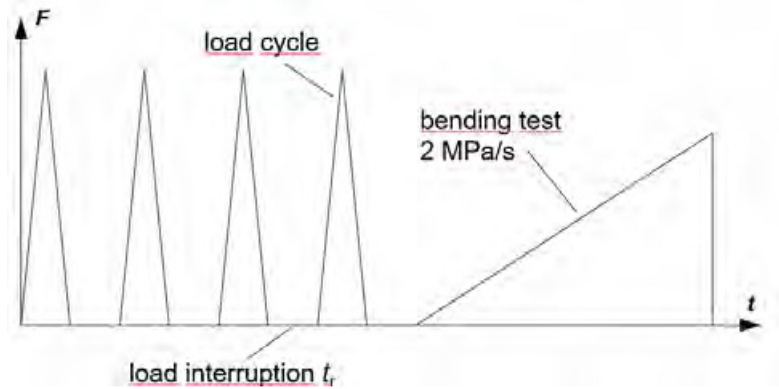

Fig. 7: Scheme for testing samples with stress free intervals by load interruption between load cycles and final ramp loading, load interruption $1 h, 1 d, 1$ week

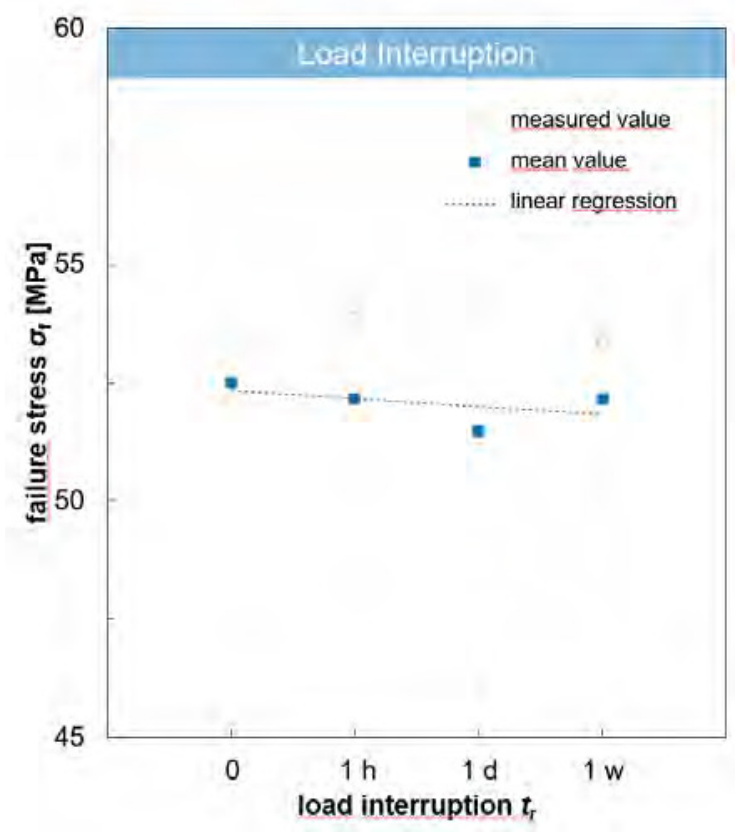

Fig. 8: Influence of stress free intervals on the tensile strength of annealed glass in ambient conditions $\left(23^{\circ} \mathrm{C}, 50 \% \mathrm{RH}\right)$ 


\section{Engineering model for cyclic fatigue lifetime prediction}

To determine the service lifetime of the glass under cyclic fatigue, an empirical power law can be used that predicts the subcritical crack growth and has been very discussed in science for almost fifty years for dynamic fatigue at constant stress rates [8]. The decisive parameter is the crack propagation coefficient or crack growth exponent $n$, which represents the slope of the straight line for the region $I$ in Fig. 10. The value of $n$ is typically between $n=10$ and $n=18$ for glasses in dynamic fatigue. It can be converted into an equivalent constant load, which leads to failure by integrating an arbitrary stress function in analytical models (Fig. 9). Alternatively, the crack growth can be calculated in discrete time steps for the load function (Fig. 10). Fig. 11 shows that the lifetime prediction with the analytical model gives a very good prediction; Fig. 12 shows that the crack growth exponent $n_{c}$ decreases for cyclic fatigue by about $10 \%$ compared to dynamic fatigue with a ramp loading.

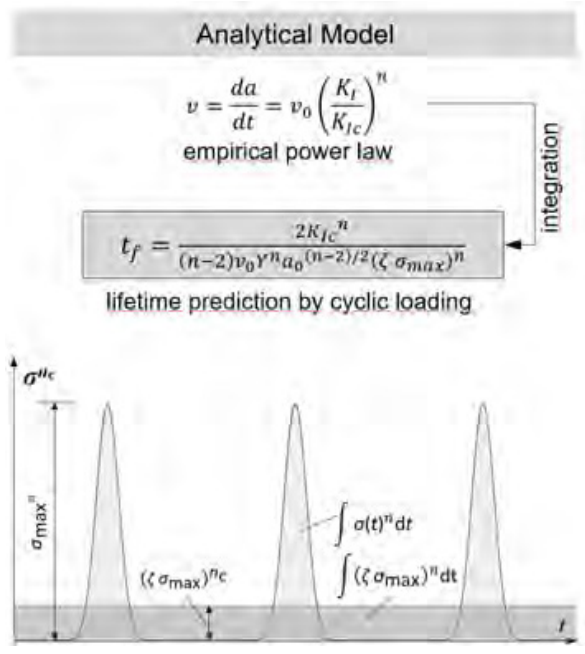

Fig. 9: Analytical for lifetime prediction based on crack growth for region I

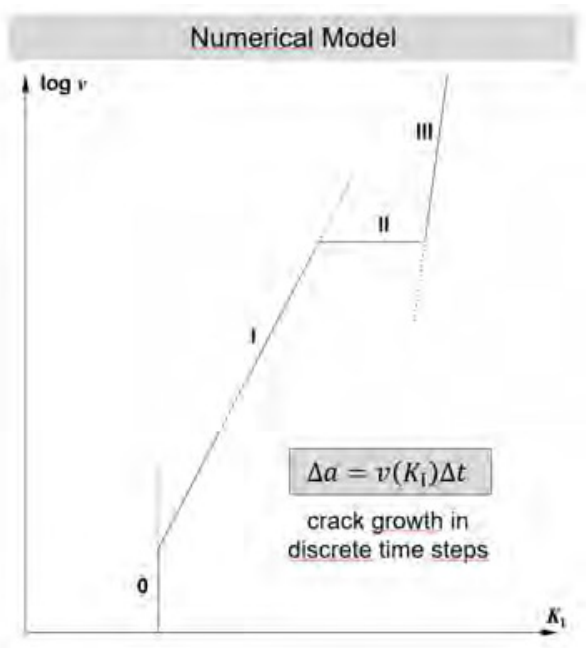

Fig. 10: Numerical model for lifetime prediction based on crack growth for region I

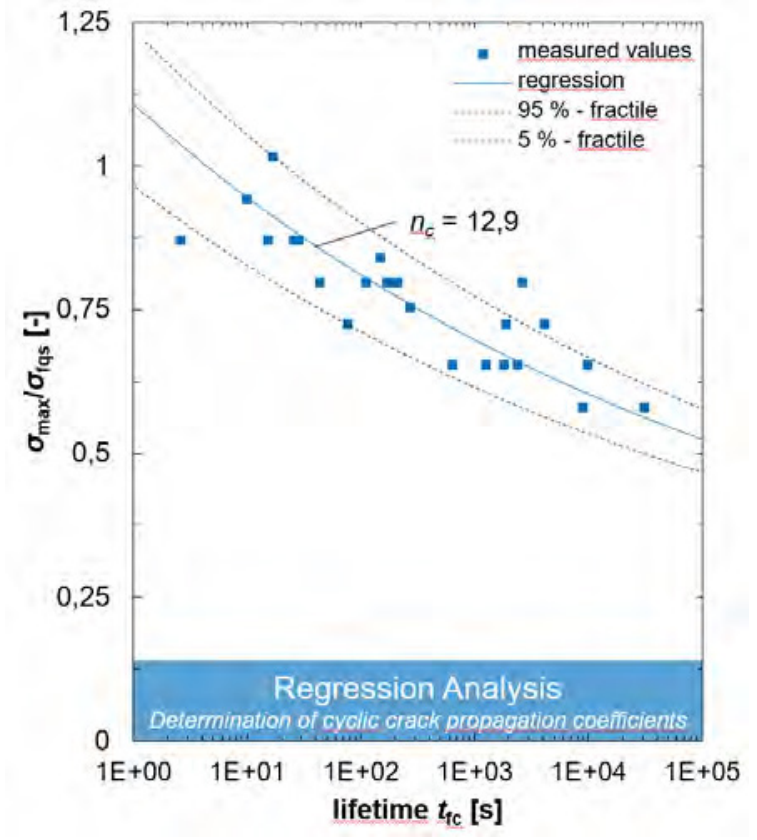

Fig. 11: Comparison between experimental data and analytical lifetime prediction with confidence intervals for $n_{c}$

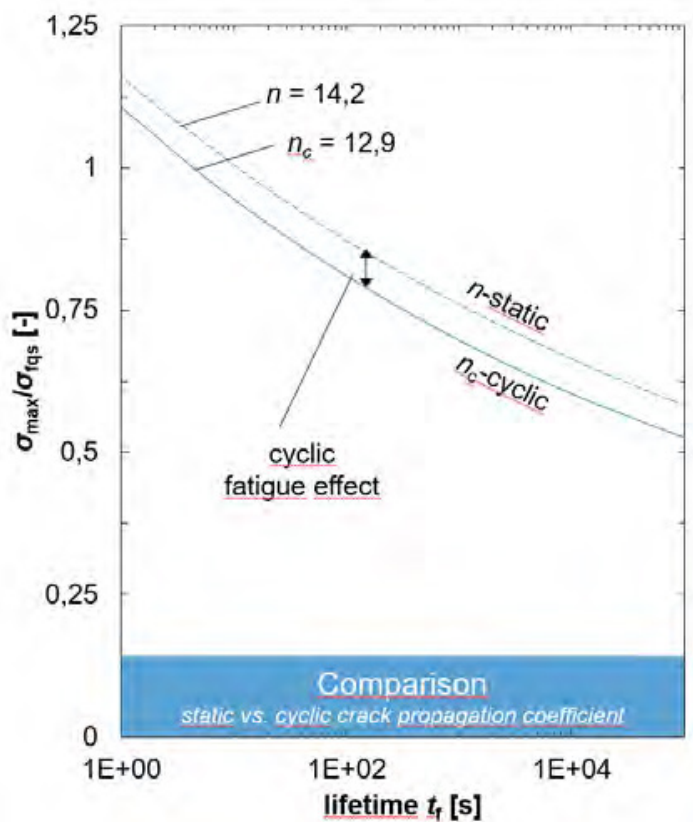

Fig. 12: Crack growth exponents for dynamic fatigue $n$ and for cyclic fatigue $n_{c}$ 


\section{Fatigue limit and design concept}

Based on the numerical model, the fatigue limit below which crack growth stops can also be validated in comparison with the experimental data. A threshold of $K_{I 0}=0.26 \mathrm{MPa} \mathrm{m} \mathrm{m}^{1 / 2}$ was derived from the experimental data using the numerical model (Fig. 13). This value is in very good agreement with literature values [8-11].

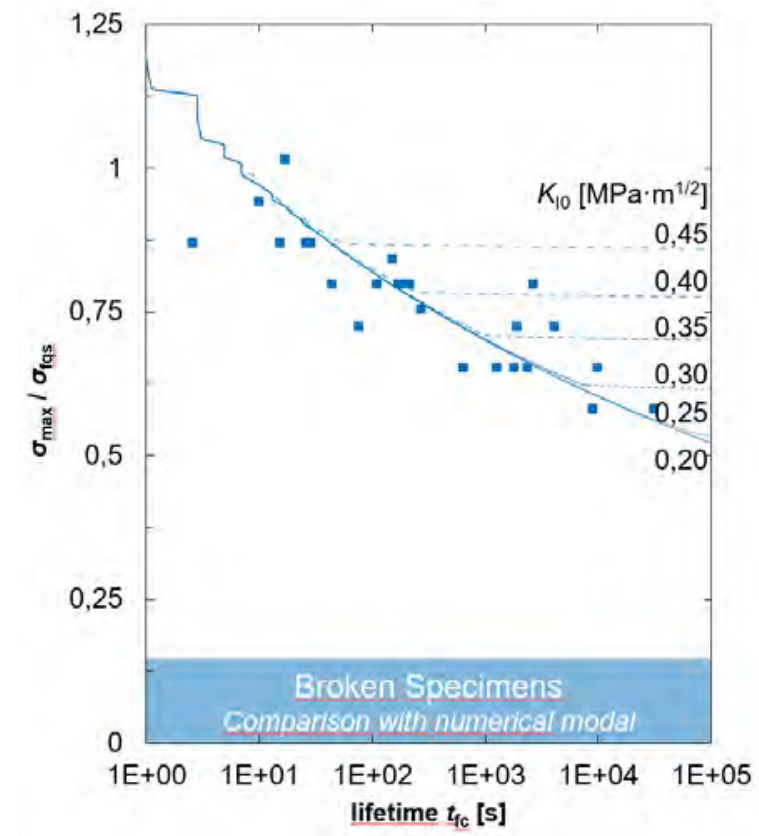

Fig. 13: Determination of the fatigue threshold $K_{I 0}$ with the numerical model

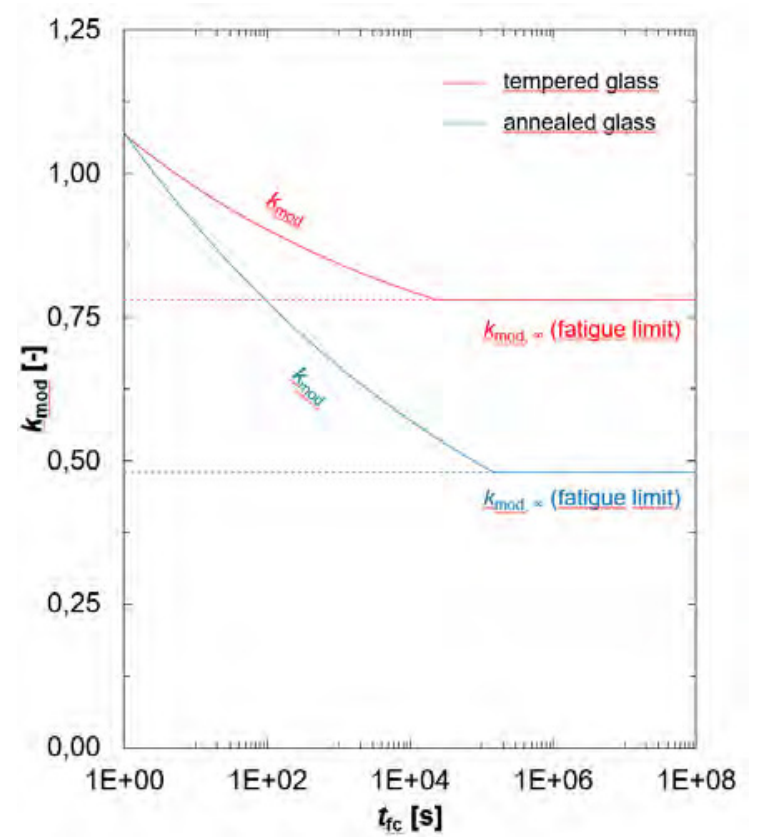

Fig. 14: Function of $k_{\text {mod }}$ for the design concept according to DIN 18008 (eq. 3)

The design concept according to DIN 18008 [7] can be used for the transfer of the results into construction practice. According to DIN 18008-1, section 8.3.7, the design resistance of glass, expressed in stress values, reads:

$$
R_{\mathrm{d}}=\frac{k_{\mathrm{mod}} \cdot k_{\mathrm{c}} \cdot f_{\mathrm{k}}}{\gamma_{\mathrm{M}}}
$$

where:

$R_{d} \quad$ design resistance (stress value)

$k_{\text {mod }}$ modification factor for stress duration, see Fig. 14

$k_{\mathrm{c}}$ construction factor related to the failure consequence

$f_{k} \quad$ characteristic material strength from standardized tests $(5 \%$-fractile)

$\gamma_{M}$ partial safety factor for the material strength

To take into account the influence of the type and duration of the cyclic action, the modification factor for stress duration $k_{\text {mod }}$ can be determined as follows:

$$
\begin{gathered}
k_{\mathrm{mod}}=\frac{c_{1}}{\left(t_{\mathrm{fc}} \zeta^{n}\right)^{1 / n_{\mathrm{c}}}}+c_{2} \\
t_{\mathrm{fc}}=T \cdot N
\end{gathered}
$$

where:

$c_{1}, c_{2}$ constants (see table 2)

$n_{\mathrm{c}} \quad$ crack growth exponent for glass in cyclic fatigue (see table 2 for soda-lime-silica glass)

$\zeta \quad$ loading coefficient for the type of load function, on the safe side $\zeta=1$

$t_{f c} \quad$ design lifetime $[\mathrm{s}]$

$T \quad$ duration of a load cycle [s]

$N \quad$ number of load cycles

The stress coefficients $\zeta$ can be determined by integrating the effective stress of a representative load cycle. Evaluations of typical load functions can be found in [6]. To simplify $\zeta=1$ is a safe assumption.

Table 2: Coefficients for the calculation of $k_{\text {mod }}$

\begin{tabular}{|c|c|c|c|}
\hline Glass type & $\boldsymbol{c}_{\mathbf{1}}$ & $\boldsymbol{c}_{\mathbf{2}}$ & $\boldsymbol{n}_{\boldsymbol{c}}$ \\
\hline $\begin{array}{c}\text { Annealed Glass } \\
\text { (ANG) }\end{array}$ & 0,90 & 0,09 & 12,9 \\
\hline $\begin{array}{c}\text { Thermally Tempered } \\
\text { Glass (FTG) }\end{array}$ & 0,33 & 0,60 & 10,5 \\
\hline
\end{tabular}




\section{Conclusions}

Based on the experimental work and theoretical models it could be shown that a lifetime prediction for sodalime-silica glass subjected to cyclic fatigue is possible using crack growths models from dynamic loading, where a ramp load is typically applied. This finding was integrated in a simplified engineering design concept based on stress design. Still, the crack growths exponent for soda-lime-silica glass derived in the experimental campaigns with cyclic loading is about $10 \%$ smaller compared to dynamic loading. Moreover, it could be shown that unlike in strength tests with singular, quasistatic re-loading, a periodic loading with load free intervals does not lead to a strength increase by crack healing effects. Future works are planned to investigate the crack growths exponent in cyclic loading for other glasses like borosilicate glass and alumino-silicate glass and to study crack healing effects more in detail, also in combination with thermal and chemical tempering at elevated temperatures up to the transformation temperature of the glass.

\section{References}

1. CEN-TS Structural Glass Parts 1, 2, 3, Comité Européen de Normalisation (2018).

2. C. Gurney, S. Pearson, Proc. Roy. Soc. of London. Series A. Math. and Phys. Sciences 192 (1948) 1031, 537-544

3. B.-T. Lü, Theor. and Appl. Frac. Mech. 27 (1997) 2, 107-114

4. V.M. Sglavo, M.T. Gadott, T. Michelet, Fatigue \& Frac. of Eng. Mat. \&Struct 20 (1997) 8, 1225-1234

5. Ö. Bucak, H. Ehard, M. Feldmann, B. Hoffmeister, K. Langosch, F. Kemper, I. Mangerig, P. Ampunant, Schallschutzelemente aus Glas an Eisenbahnstrecken. Brückenbau - Construction \& Engineering (2012), 16-21

6. J. Hilcken, Zyklische Ermüdung von thermisch entspanntem und thermisch vorgespanntem KalkNatron-Silikatglas, Dissertation, Technische Universität Darmstadt (2015)

7. DIN 18008-1, Glas im Bauwesen - Bemessungsund Konstruktionsregeln, Teil 1, (2010)

8. S.M. Wiederhorn, L.H. Bolz, J. Am. Ceram. Soc. 53 (1970) 10, 543-548

9. E. Gehrke, C. Ullner, M. Hähnert, J. Mat. Science 26 (1991) 20, 5445-5455

10. K.-T. Wan, S. Lathabai, B.R. Lawn, J. Europ. Ceram. Soc 6 (1990) 4, 259-268

11. C. Kocer, R. Collins, J. Am. Ceram. Soc 84 (2001) 11, 2585-2593

12. J. Schneider, S. Schula, W.-P. Weinhold, Thin Solid Films. 520 (2012) 12, 4190-4198
13. S. Schula, Charakterisierung der Kratzanfälligkeit von Gläsern im Bauwesen, Dissertation, Technische Universität Darmstadt (2015)

14. EN 572-1, Glass in building, Basic soda-lime silicate glass products, Part 1, (2012)

15. C. Ullner, L. Höhne Untersuchungen zum Festigkeitsverhalten und zur Rissalterung von Glas unter dem Einfluss korrosiver Umgebungsbedingungen, Bericht Nr. 43 D (1993)

16. W.-T Han, M. Tomozawa, J. Am. Ceram. Soc. 72 (1989) 10, 1837-1843

17. GlassStress Ltd., Scattered Light Polariscope SCALP-04 Instruction Manual Vers. 4.5.1

18. K.C. Datsiou, M. Overend, Glass Struct Eng 2 (2017) 105

19. A. Fink, Ein Beitrag zum Einsatz von Floatglas als dauerhaft tragender Konstruktionswerkstoff im Bauwesen, Dissertation, Technische Universität Darmstadt (2000) 